\title{
As imagens literárias na escrita de Mia Couto e a pintura expressionista alemã
}

\author{
Enilce Rocha Albergaria e Rejane Granato Santos \\ Universidade Federal de Juiz de Fora
}

RESUMO: ESTE ESTUDO ANALISA POSSÍVEIS CONVERGÊNCIAS ENTRE OS ROMANCES TERRA SONÂMBULA E A VARANDA DO FRANGIPANI, DE MIA COUTO, E O EXPRESSIONISMO ALEMÃO DO INÍCIO DO SÉCULO XX, CONSIDERANDO ESTE ÚLTIMO UMA RESPOSTA ESTÉTICA À MODERNIDADE ENQUANTO AMEAÇA À SENSIBILIDADE E À LIBERDADE DO HOMEM, E OS PRIMEIROS COMO TEXTOS LITERÁRIOS MARCADOS PELOS CONFLITOS CULTURAIS ENTRE OS VALORES DA MODERNIDADE E AS CULTURAS TRADICIONAIS DAS COMUNIDADES ÉTNICAS DE MOÇAMBIQUE.

ABSTRACT: THIS ESSAY SHOWS THE POSSIBLE SIMILARITIES BETWEEN THE NOVELS TERRA SONAMMBULA AND A VARANDA DO FRANGIPANI, BY MIA COUTO, AND THE GERMAN EXPRESSIONISM OF THE BEGINNING OF THE XX CENTURY, CONSIDERING THE LATTER AS AN AESTHETIC RESPONSE TO MODERNITY FELT AS A MENACE TO MANKIND'S SENSIVITY AND LIBERTY, AND THE FORMERS AS LITERARY PIECES MARKED BY THE CULTURAL CONFLICTS BETWEEN THE MODERNITY VALUES AND THE TRADITIONAL CULTURES OF THE MOZAMBICAN ETHNIC COMMUNITIES.

PALAVRAS-CHAVE: MIA COUTO - EXPRESSIONISMO - ROMANCE MOÇAMBICANO LITERATURA E ARTES PLÁSTICAS - TRADIÇÃO X MODERNIDADE KEY-WORDS: MIA COUTO - EXPRESSIONISM - MOZAMBICAN NOVEL - LITERATURE AND PAINTING - TRADITION X MODERNITY 
este estudo propomos um diálogo entre imagens literárias selecionadas nos romances Terra sonâmbula (1995) e A varanda do Frangipani (1997), do escritor moçambicano Mia Couto, e a estética da pintura expressionista alemã do início do século XX. Para tanto, consideraremos aspectos formais e temáticos da escrita desse autor e do movimento expressionista alemão que nos parecem apresentar convergências para além da distância histórica e cultural, pois, como sabemos, os movimentos estéticos das artes e das letras, como tantos outros legados da civilização ocidental, tornaram-se um patrimônio comum dos artistas, poetas e escritores representativos da grande diversidade das culturas contemporâneas. A fim de estabelecer uma proximidade entre a estética expressionista e a escrita de Mia Couto, tentaremos propor um recorte conciso das principais características desse movimento que consideramos pertinentes para o nosso estudo, a despeito das imensas confusões existentes em torno da utilização do termo "expressionismo" por parte dos historiadores e estudiosos da arte.

Entende-se que a corrente artística comumente designada como expressionismo tenha surgido em 1905, com o movimento alemão Die Brücke (A ponte), criado por um grupo de jovens pintores na cidade de Dresden. A poética desses artistas residia, sobretudo, na proposta de uma nova forma de ver e abordar a realidade circundante, baseada num confronto direto entre o artista e o mundo.

Ao observarmos nos dois romances de Mia Couto acima assinalados as imagens literárias construídas a partir do ponto de vista do narrador e/ou da(s) personagem(ns), constatamos, no âmbito da escritura, a recorrência de imagens que descrevem um mundo em ruínas no qual se imprimem as marcas da morte e da destruição. Ora, em muitas dessas imagens, a visão do narrador e/ou da(s) personagem(ns) parece se expressar através da contradição. Ou seja, o olhar, sob o impacto das imagens da destruição e da morte, ao mesmo tempo em que possibilita o acesso imediato ao real, se mostra uma quase impossibilidade, uma vez que revela o cenário caótico da guerra e da nação de Moçambique na sua mais absoluta nudez. E a impressão do leitor é a de que a visão do narrador e/ou da personagem parece se diluir devido à contaminação mútua entre as impressões do "real" e os sentimentos que permeiam o ato de ver.

É nessas imagens diluídas, difusas, que identificamos uma forma de representação que nos remete a algumas pinturas pertencentes à corrente 
expressionista das vanguardas européias. Na concepção estética dos pintores expressionistas, a imagem representada deveria estar impregnada pelas emoções do artista, e, para diluir as fronteiras entre a subjetividade e a exterioridade, o expressionismo propunha um contato imediato com o "real". Daí as imagens pictóricas resultantes expressarem uma certa ambigüidade, pois, ao mesmo tempo em que o pintor pretende olhar a realidade sem a presença de filtros mediadores, a imagem resultante desse confronto perde sua objetividade e sua nitidez, devido à interferência das emoções no gesto pictórico. A pintura não busca a representação, mas a expressão do real, e, como tal, traz em si todos aqueles elementos que atuam e interferem na relação sujeito/objeto. O historiador da arte Giulio Carlo Argan assinala esse conflito decorrente da relação imediata entre sujeito e objeto nos seguintes termos: "Para os artistas da Brücke a solução é um romantismo entendido como condição profunda, existencial do ser humano: a ânsia de possuir a realidade e a angústia de ser arrastado e possuído pela realidade que se aborda" (ARGAN, 1992: 228).

Assim sendo, no expressionismo, a relação entre o pintor e a realidade sofre uma transformação sem precedentes. A abordagem direta do real, proposta por esses artistas, ao contrário do que havia sido explorado pelas artes da representação até aquele momento, não apenas admite como também pressupõe a presença da subjetividade no ato pictórico, porque o artista expressionista não pretende apenas retratar o real: ele deseja se misturar a ele, contaminá-lo com suas emoções e com seu inconsciente. Por esse motivo, as pinturas expressionistas, muitas vezes, adquirem um aspecto soturno, ou rude, ou mesmo quase caricatural, impregnadas pelos fantasmas de uma civilização que pretende anular quaisquer vestígios de uma existência "outra" que não se ajustem perfeitamente ao ideal por ela proposto. As emoções passam a interferir no gesto pictórico, comprometendo a objetividade da representação e gerando, dessa maneira, a deformação da imagem. Trata-se, portanto, de uma subversão da idéia cartesiana de consciência, segundo a qual o sujeito pensante tem acesso à realidade de uma forma distanciada e analítica, sem com ela se misturar.

As deformações e o aspecto grotesco configurados na pintura expressionista são também o reflexo de um contexto histórico no qual a modernidade começa a ser sentida como uma ameaça à sensibilidade e à liberdade do ho- 
mem, contexto no qual predominam a instabilidade e a ansiedade diante de um grande número de transformações vividas pela sociedade da época. Dessa maneira, a estética e as temáticas expressionistas, ao imprimirem uma modificação intensa nos modos de perceber e representar a realidade circundante, suscitavam o questionamento dos valores e das transformações da sensibilidade e do comportamento humano que vinham sendo levados a cabo pela modernidade e pelo progresso tecnológico. Cabe ressaltar ainda que, através da deformação das imagens retratadas, os pintores expressionistas, além de instaurar o questionamento em face dessas transformações, propunham um retorno à antiga união entre o homem e a natureza, conforme explica o pintor Franz Marc, que propõe um deslocamento do sujeito para a matéria mesma representada:

Existe idéia mais misteriosa para o artista do que imaginar como a natureza se reflete nos olhos de um animal? Como um cavalo vê o mundo? E uma águia? E um corço? E um cachorro? Como é mesquinha, desalmada, a atitude por nós convencionada de dispormos animais em uma paisagem tal como a vemos, ao invés de nos aprofundarmos na alma do animal para tentarmos vislumbrar a forma como ele vê o mundo. (MARC, 1993: 178)

Nesse sentido, um dos artistas que mais influenciaram a arte expressionista foi o holandês Vincent Van Gogh (1853-1890), devido à sua forte paixão pela natureza. Esse fascínio aparece em sua pintura por meio do uso de cores fortes e linhas sinuosas, cujo efeito místico revela a tentativa do pintor de expressar a união simbólica Homem - Natureza - Universo. De acordo com Alice Brill (2002), o procedimento pictórico utilizado por Van Gogh teve grande repercussão no expressionismo graças à acentuação do contorno e do perfil do retrato e ao uso de linhas fluidas e circulares, cujo resultado foi a distorção da imagem e a eliminação dos detalhes. Os pintores expressionistas, por sua vez como Gauguin, Hodler, Munch, Toulouse-Lautrec, Toorop e Thorn-Prikker , ao assimilarem essas inovações, conseguiram imprimir maior espiritualidade a seus quadros, e, assim, as formas representadas de homens e animais harmonizavam-se com a energia e a movimentação incessante da natureza.

Além da distorção formal e da agressividade do gesto pictórico - que se manifesta por meio de pinceladas, de manchas, do excesso de tinta e de 
cores -, as pinturas expressionistas se caracterizam também por expressarem uma visão muitas vezes pessimista da realidade, aliada a um gosto pelo grotesco e pelo sobrenatural. A essas características acrescenta-se a busca por uma expressão mais espontânea e autêntica, devido a uma espécie de recusa por parte desses artistas da linguagem constituída a priori. Daí decorre o aspecto selvagem e primitivo dessas pinturas, em muitas das quais a representação acaba se reduzindo a esquemas básicos e elementares, como no caso da obra de Vassili Kandinsky (1866-1944).

$\mathrm{O}$ anseio desses artistas residia, principalmente, em se rebelar contra a imposição dos valores tecnicistas predominantes na sociedade industrial. $\mathrm{O}$ pensamento totalizador que regia a ideologia progressista da época propunha um distanciamento cada vez maior do mundo natural, tendo como conseqüência a mecanização da experiência humana e uma anulação crescente dos aspectos emocionais do indivíduo. Assim, como reação ao materialismo da época, os artistas propuseram um mergulho na interioridade do sujeito, com o objetivo de trazer à tona não apenas a emoção, mas, também, todos aqueles aspectos da existência que se encontravam subjugados pelo ideal de civilização proposto, sobretudo, pela ideologia iluminista. Para a historiadora de arte Karin Thomas, esse movimento artístico pode ser considerado como uma reação "à situação instável do clima social em todas as regiões européias". Segundo a autora:

Culturalmente, essa época oscilava entre presságios apocalípticos e uma nova consciência do indivíduo; politicamente, entre as estruturas desgastadas da tradição monárquica, na Alemanha, e as idéias radicais de uma sociedade revoltada, que pretendia apoderar-se do poder. Não é de admirar que na luta entre essas energias espirituais antagônicas tenha surgido um imenso campo de tensão, contendo, ao mesmo tempo, a representação apavorante da grande cidade que gera depravação, do poder de destruição da guerra e do sonho eufórico de um homem "novo" com uma visão paradisíaca de reaproximação entre o homem e a natureza. (THOMAS apud BRILL, 2002: 401)

Essa tentativa de restauração do elo perdido entre homem e mundo conduz a arte expressionista ao encontro daquelas culturas que se caracterizavam por possuir modos de vida e valores diversos daqueles sobre os quais a 
cultura européia se solidificara. O principal exemplo dessa busca pela alteridade por meio do encontro com culturas ainda não contaminadas pelo ideal da civilização ocidental encontra-se na obra de Paul Gauguin. Insatisfeito com os valores da sociedade européia, esse artista viaja para o Taiti, movido pelo desejo de uma vida mais espontânea e autêntica, baseada em uma maior cumplicidade com os elementos do mundo natural. De acordo com Pierre Francastel, Gauguin:

Ocupa um lugar único na história das transformações do espaço moderno, além de ter o mérito de aproximar as civilizações [...] rompeu materialmente o conceito antigo de espaço: tornando-nos cientes e curiosos dos procedimentos e símbolos que determinam, através das obras figurativas, os costumes e a conduta dos grupos sociais. (FRANCASTEL apud BRILL, 2002: 395)

O movimento expressionista alemão teve em Gauguin uma de suas principais influências. $\mathrm{Na}$ busca pelo desenvolvimento de uma "arte nova", os pintores pertencentes a esse grupo também buscavam inspiração nas artes primitivas da África e da Oceania, além da arte impressa da Idade Média Tardia. A espontaneidade e a força criativa presentes nas xilogravuras desenvolvidas pelas culturas primitivas tornaram-se o ideal estético dos expressionistas, que começaram também a se dedicar à arte da xilogravura. Assim sendo, é possível afirmar que grande parte daquilo que entendemos por arte expressionista se constitui, basicamente, em uma tentativa de retorno à espontaneidade criativa presente nas culturas ainda não contaminadas pela racionalidade européia.

Intuímos que alguns dos processos narrativos utilizados por Mia Couto na construção de imagens literárias que narram a emoção provocada pelo impacto de um mundo em ruínas se aproximam das estratégias pictóricas presentes na pintura expressionista. Os aspectos dialógicos que percebemos entre processos estéticos presentes na construção de certas imagens literárias de Mia e a pintura expressionista podem explicar-se a partir de questões históricas convergentes. Assim, se a estética expressionista emerge como uma crítica à modernidade européia num momento histórico de tensões culturais e políticas antagônicas, nutrindo-se do sonho utópico de um homem novo em fusão com a natureza, a escrita de Mia insere-se em um contexto histórico de 
imbricação conflituosa entre as tradições das culturas das diferentes etnias de Moçambique e a irrupção da modernidade na nação moçambicana, já que as narrativas de Terra sonâmbula e $A$ varanda do Frangipani são permeadas pela fratura cultural gerada pela invasão dos valores da modernidade em confronto com aqueles pertencentes às tradições das comunidades étnicas que compõem a diversidade cultural da nação.

\section{As imagens expressionistas na escrita de Mia Couto: a função narrativa das cores e da água}

Identificamos nas narrativas dos romances Terra sonâmbula (1995) e $A v a$ randa do Frangipani (1997) uma recorrência de imagens literárias nas quais estão presentes as cores vermelha e preta. Nelas o uso dessas cores opera a transformação da cor - enquanto "lugar-comum" (com hífen) - em criação poética que instaura o novo, ou seja, aquilo que Glissant (2005) denomina de "lugar comum" (sem hífen). ${ }^{1}$

Se a pintura expressionista se utiliza largamente das cores vivas como veículos da emoção, na escrita de Mia Couto o vermelho e o negro estão presentes de forma recorrente e expressam a intensidade dos sentimentos humanos, a desesperança, o cenário de ruínas materiais, culturais e psicológicas. Sua utilização narrativa nos evoca as pinceladas, as manchas e os excessos de tinta e de cores presentes na pintura expressionista. Vertidos sobre a frase, o vermelho e o negro - as cores que conotam a morte e a destruição - impregnam toda a imagem literária: seres humanos, casas, objetos perdem sua individualidade, seus contornos, e desaparecem, amalgamados. A ausência das cores que conotam a vida é também assinalada no texto de Mia pela ênfase concedida às descrições da noite - a cor negra das trevas. A escuridão dilui os contornos e as formas, provocando a contaminação e a indistinção

\footnotetext{
1 “'Lugares-comuns' são partículas efêmeras em divagação neste nódulo frio que é a comunicação: todas as idéias estão no ar, mas, sobretudo, o que importa é a sua manifestação pública e se possível exagerada ou simplificada (dessa maneira, o 'lugar-comum' constitui, com esse traço de união entre os dois termos que o articulam, que o constituem, a transformação espetacular dessa necessidade poética, aberta e misteriosa que é o 'lugar comum')" (GLISSANT, 1990: 190, trad. nossa).
} 
entre o universo interior das personagens e o mundo exterior, conforme podemos observar nas seguintes imagens:

"A noite decorre de olhos abertos, vigilantes" (COUTO, 1995: 60); "Despertei no meio da noite, ainda o escuro não se apagara" (COUTO, 1995: 72); "Ficou cega para olhar as trevas" (COUTO, 1997: 13); "A gente toca o tronco e sente o sangue da terra circulando em nossas íntimas veias" (COUTO, 1997: 68); "Você está a sangrar em todas as suas pernas, Nãozinha" (COUTO, 1997: 92); "No enquanto, lá fora, tudo vai ficando noite. Reina um negro silvestre, cego. Muidinga olha o escuro e estremece. É um desses negros que nem os corvos comem. Parece todas as sombras desceram à terra" (COUTO, 1995: 13); "Era noite quando a canoa desatou caminho. O escuro me fechava apagando os lugares que foram meus" (COUTO, 1995: 39).

$\mathrm{O}$ vermelho do sangue e o negro da cegueira humana e das sombras contaminam o imaginário humano e tornam-se maiores do que os homens, maiores do que o mundo e a vida que o imaginário apequena. As imagens e as cores da morte se dilatam, se movimentam, recobrindo a vida, que se torna miserável, reduzindo ao silêncio a voz humana - suas estórias e sonhos:

Sonhar? Ri-me. O velho Mourão acreditava que só sonhava quando sangrasse. Ele insistia que era verdade. $\mathrm{O}$ sonho não lhe vinha se não corresse esse vermelho de dentro. (COUTO, 1997: 71)

Cinzentos, da cor dos mortos, os vampiros enevoaram o mundo. Um eclipse, parecia. Os bichos rasaram as casas, exibindo dentes e mandíbulas. Se escutaram suas asas como manuais helicópteros militares. Os velhos, aflitos, se abrigaram. Então, os morcegos desataram a atacar as andorinhas. Em plenos ares, eles as devoravam. E eram tantas as avezinhas sacrificadas que respingavam gotas vermelhas em toda parte. As plumas dançavam pelos ares, caindo com gentileza sobre o chão. Parecia que depenavam as próprias nuvens. Nesse dia, choveu tanto sangue que o mar todo se tingiu. (COUTO, 1997: 137)

$\mathrm{Na}$ utilização narrativa desse movimento entre a ausência e a presença das cores, ao descrever o aspecto descolorido da paisagem dilacerada pela guerra, a escrita - graças à alteração inusitada para o leitor do sintagma verbal - reinventa, por meio do colorido imaginado, o elo entre o passado e o futuro utópico, inscrevendo na presença das cores a conotação da antiga 
harmonia e inseparabilidade existente nas culturas tradicionais entre homem e natureza:

Muidinga imaginava como será uma aldeia, essas de antigamente, cheinhas de tonalidades. As colorações que devia haver na vila de Kindzu antes da guerra desbotar as esperanças?! Quando é que cores voltariam a florir, a terra arcoiriscando. (COUTO, 1995: 44; grifo nosso)

Gostaríamos de ressaltar ainda um outro universo semântico extremamente presente na escrita de Mia Couto que confere à imagem uma nítida evocação das representações presentes na pintura expressionista. Trata-se das inúmeras referências à água enquanto materialidade e também enquanto coloração - a água luz, a água palavra azul, a água vermelha: "Pudesse eu para sempre residir em matéria líquida de espraiar, rio em estuário, mar em infinito" (COUTO, 1995: 86).

Aquelas luzes ficavam - a flutuar nas ondas e eram brilhos avermelhando as espumas. Marta parecia inclinada a poesias. Disse que a luz era mais leve que a água. Seus reflexos ficam boiando como peixes lunares, algas de fogo - São assim as memórias destes velhos, flutuando mais leves que o tempo. (COUTO, 1997: 100)

"Onde o mar se abre como uma palavra azul" (COUTO, 1995: 50); "As minhas lembranças são seres morridos, sepultados não em terra mas em água. Remexo nessa água e tudo se avermelha" (COUTO, 1997: 81).

As imagens da água, assim como as imagens noturnas, denotam uma espécie de ofuscamento da realidade, conferindo-lhe um aspecto ora diluído, ora turvo, fato esse que as aproxima, mais uma vez, das manchas e da aparência sombria presentes nas pinturas expressionistas.

\section{A linguagem e a tradução do vivido}

Tanto na arte expressionista quanto na escrita de Mia Couto identificamos uma certa insatisfação em relação à linguagem constituída, estruturada. Nesse 
sentido, tanto a linguagem pictórica quanto o sistema da língua parecem constituir-se a partir de um fracasso, sobretudo no que tange à possibilidade de uma tradução dos estados da alma e da expressão do verdadeiro "estar no mundo". Se na arte expressionista essa insatisfação se manifesta por meio de um desejo incontido de resgatar o gesto criativo originário, na escrita de Mia um dos principais recursos narrativos utilizados para suprir as lacunas da linguagem encontra-se na presença recorrente das imagens literárias e na inserção da oralidade na escrita. Em relação aos anseios estéticos dos artistas pertencentes ao movimento expressionista, Argan assinala que:

Para ser criação do real a arte deve prescindir de tudo o que preexiste à ação do artista: é preciso começar a partir do nada. A experiência de mundo do artista não difere, em sua origem, da de qualquer outra pessoa. É esse o material sobre o qual opera o artista: os temas dos expressionistas alemães geralmente estão ligados à crônica da vida cotidiana (a rua, as pessoas nos cafés, etc.). Em suas obras, porém, percebe-se uma espécie de incômodo, de indisfarçada rudeza, como se o artista nunca tivesse desenhado ou pintado antes daquele momento. Por que se recusa toda linguagem constituída, por que a expressão se dá de modo exageradamente penoso, excessivo, sem nuances? $\mathrm{Na}$ origem da linguagem não existem palavras que tenham um significado, mas, apenas sons que assumem um significado. O Expressionismo alemão pretende ser precisamente uma pesquisa sobre a gênese do ato artístico: no artista que o executa e, por conseguinte, na sociedade a que ele se dirige. (ARGAN, 1992: 237)

Uma relação semelhante à estabelecida pelo crítico Argan entre as aspirações presentes na arte expressionista e a origem da linguagem pode também ser observada na escrita de Mia. O aspecto sinestésico adquirido por algumas das imagens presentes em sua narrativa apresenta uma grande convergência com o processo pictórico adotado pelos artistas expressionistas. Assim, por exemplo, na seguinte imagem: "Grãos e gotas se misturavam nos lábios. Não sabia que tristezas se me enrolavam na garganta” (COUTO, 1997: 106), podemos observar uma espécie de fusão entre as emoções do personagem e elementos do mundo concreto, e uma mistura de sensações corpóreas e sentimentos contidos. Pensamos que tanto na arte expressionista quanto na imagem literária esse recurso pode estar associado a uma tentativa de 
integração corpo-linguagem, partindo do princípio de que é por meio da visão e dos demais sentidos que apreendemos o mundo e vivenciamos nossas experiências. Assim, na escrita de Mia o corpo - suas secreções, seus desejos, o sangue vertido - é invocado, sobretudo, por meio da linguagem imagética.

Um outro aspecto igualmente relevante na escrita de Mia em relação à fusão do elemento corpóreo à linguagem encontra-se no desejo de restauração daquelas possibilidades expressivas suprimidas na passagem das culturas orais para a escrita, pois as culturas orais caracterizam-se por permitir à linguagem uma fusão com o universo da experiência concreta, bem como o não-distanciamento em relação ao existente sempre em mutação. Podemos detectar na narrativa de Mia Couto a presença do corpo na escrita, como no seguinte exemplo: "Eu sei, estou enchendo de saliva sua escrita. Mas, no fim, o senhor vai entender isto que estou para aqui gargantear" (COUTO, 1997: 29). Nesse fragmento de texto os elementos corpóreos são invocados para significar a inclusão do excedente suprimido na passagem da linguagem concreta das culturas orais para a escrita, devolvendo-lhe a fusão com a matéria do mundo. Ora, o resultado desse processo remete-nos, mais uma vez, ao movimento expressionista da arte européia no que tange às tentativas, presentes nesses artistas, de um reingresso do corpo na cultura e na arte. Isso porque, no momento histórico em questão - a virada do século XX -, a dimensão corporal do humano se encontrava apartada da experiência, represada por uma cultura pautada na racionalidade e na dicotomia matéria/espírito.

Referindo-se às relações entre o expressionismo e a psicanálise, Maria Inês França analisa a presença do corpo no âmbito dessa corrente estética. A autora visualiza na arte expressionista um "excesso pulsional" que se materializa em um “exceder-se em linguagem”. De acordo com a autora:

A cultura, em geral, não espera nem acolhe esses excessos; eles são efeito de ruptura que tendem a empurrar os limites da linguagem no seu valor expressivo. Essa impulsão, uma criação de realidade, representa e se apresenta na materialidade da obra de arte expressionista, determinando uma íntima relação da obra como criação de realidade e a subjetividade livre das construções do já conhecido, como se formasse um só tecido e não houvesse diferença entre o corpo do artista e a 
produção em arte que fabrica, corrigindo o efeito de alienação do próprio corpo que o recalque originário determina. (FRANÇA, 2002: 129)

O desejo de reinstalar o corpo na linguagem, presente na arte expressionista, encontra em Mia Couto uma outra dimensão. Esta reside numa tentativa de reaproximar a língua portuguesa das culturas orais moçambicanas, conforme nos explica o autor:

Venho brincar aqui no português, a língua. Essa que dá gosto a gente namorar e que nos faz a nós, moçambicanos, ficarmos mais Moçambicanos. Que outros pretendam cavalgar o assunto para fins de cadeira e poleiro pouco me acarreta. A língua que eu quero é essa que perde função e se torna carícia. O que me apronta é o gosto da palavra, o mesmo que a asa sente aquando o vôo. Meu desejo é desalisar a linguagem, colocando nela as quantas dimensões da Vida. E quantas são? Se a vida tem é idimensões. Assim, embarco nesse gozo de ver como escrita e o mundo mutuamente se desobedecem... Estamos criando uma língua apta para o futuro, veloz como a palmeira, que dança todas as brisas sem deslocar seu chão. Língua artesanal, plástica, sem a arrogância sequer de estar certa ou de se querer com graça. (COUTO apud ANGIUS \& ANGIUS, 1998)

A materialização da linguagem a partir do grande uso de metáforas presentes no texto propicia, mais uma vez, a articulação entre a escrita em questão e os ideais sobre os quais se estabelece a arte expressionista. Em relação à função das imagens no âmbito dessa estética, França afirma que:

$\mathrm{Na}$ arte expressionista a imagem não é, ela se faz e a ação que a faz a materializa, ato com o valor simbólico de representação de um momento expressivo da cultura. Não se trata de uma linguagem para manifestar as imagens, mas uma matéria que se torna imagem e que se manifesta muitas vezes como deformação ou distorção do objeto. (FRANÇA, 2002: 129)

Em relação ao texto de Mia Couto, sua escrita insere na estrutura lingüística o conflito existente entre a língua portuguesa e a visão de mundo das culturas moçambicanas, bem como a tipologia discursiva das línguas étnicas. $\mathrm{Na}$ fala de um dos personagens do romance $A$ varanda do Frangipani, essa questão lin- 
güística é assinalada: "Me educaram numa língua que não é minha. Pesava em mim esse eterno desencontro entre palavra e idéia" (COUTO, 1997: 121).

Com efeito, na narrativa do romance $A$ varanda do Frangipani encontramos em vários fragmentos do texto a referência a uma certa impossibilidade da linguagem de expressar, por meio das palavras, a dimensão real da experiência vivida: "Primeiro me acabou o riso, depois o sonho, depois as palavras" (COUTO, 1997: 13). O sistema da língua portuguesa distancia-se da experiência concreta de uma tradição lingüística baseada na não-separação entre o homem e a natureza que a escrita de Mia objetiva restaurar, conforme podemos observar na fala de uma das personagens do romance supra citado: "Desculpe-me este meu português, já não sei que língua falo, tenho a gramática toda suja, da cor dessa terra" (COUTO, 1997: 48). Nesse sentido, o texto traz referências constantes a uma forma de expressão possuidora de uma maior correspondência com a esfera da natureza e capaz de traduzi-la, conforme podemos observar nos seguintes fragmentos: "Esse barulho é a própria noite. Você lá, de onde vem, há muito que deixou de ouvir a noite" (COUTO, 1997: 45); "Nos dias de hoje, porém, o bicho já não sabe falar a língua dos homens" (COUTO, 1997: 140); "Minha vontade estava pegajosa, minhas querências estavam atoladas no matope ${ }^{2 "}$ (COUTO, 1997: 48).

Finalizando este recorte analítico, gostaríamos de enfatizar que o nosso objetivo nesse estudo consistiu em apenas apontar alguns pontos de consonância entre a escrita literária de Mia Couto e o movimento da pintura expressionista. Contentamo-nos em assinalar aqueles aspectos que nos pareceram mais evidentes e que nos possibilitaram vislumbrar um possível aprofundamento no que tange a esse diálogo. Ressaltamos, também, que consideramos bastante instigante essa tentativa de aproximação dialógica entre diferentes sistemas de representação - no presente estudo entre a pintura e a escrita literária -, pois as representações artísticas, cuja análise é indissociável da história das culturas, podem nos ajudar a compreender a interação entre as escolhas estéticas e as questões históricas, bem como o diálogo entre as estéticas literárias póscoloniais e as estéticas da cultura ocidental.

\footnotetext{
${ }^{2}$ Matope no português de Moçambique significa "lodo", "lama".
} 


\section{Referências Bibliográficas}

ANGIUS, Fernanda \& ANGIUS, Matteo. O desanoitecer da palavra. Praia-Mindelo: Embaixada de Portugal, Centro Cultural Português, 1998.

ARGAN, Giulio Carlo. Arte moderna. Tradução de Denise Bottmann e Federico Carotti. São Paulo: Cia. das Letras, 1992.

BRILL, Alice. O Expressionismo na pintura. In: GUINSBURG, J. (Org.). O Expressionismo. São Paulo: Perspectiva, 2002.

COUTO, Mia. Terra sonâmbula. Rio de Janeiro: Nova Fronteira, 1995. . A varanda do Frangipani. 2. ed. Lisboa: Caminho, 1997.

FLEISCHER, Marion. O Expressionismo e a dissolução de valores tradicionais. In: GUINSBURG, J. (Org). O Expressionismo. São Paulo: Perspectiva, 2002.

FRANÇA, Maria Inês. A inquietude e o ato criativo. In: GUINSBURG, J. (Org.). O Expressionismo. São Paulo: Perspectiva, 2002.

GLISSANT, Édouard. Introdução a uma poética da diversidade. Juiz de Fora: EDUFJF, 2005.

Poétique de la relation. Paris: Gallimard, 1990.

GONÇALVES, Aguinaldo José. A estética expressionista na pintura e na literatura. In: GUINSBURG, J. (Org.). O Expressionismo. São Paulo: Perspectiva, 2002.

MARC, Franz. Como um cavalo vê o mundo. In: CHIPP, Herschel Browning. Teorias da arte moderna. Tradução de Waltensir Dutra. São Paulo: Martins Fontes, 1993.

MATTOS, Cláudia Valladão de. Histórico do Expressionismo. In: GUINSBURG, J. (Org.). O Expressionismo. São Paulo: Perspectiva, 2002.

OLIVEIRA, Ana Cláudia de. Expressionismo como modo de vida e moda. In: GUINSBURG, J. (Org.). O Expressionismo. São Paulo: Perspectiva, 2002.

RICOEUR, Paul. A metáfora viva. Tradução de Dion Davi Macedo. São Paulo: Loyola, 2002. 